\title{
Dynamic Scoring in a Romer-style Economy
}

\author{
Dean Scrimgeour* \\ Colgate University
}

December 27, 2011

\begin{abstract}
This paper analyzes how changes in tax rates affect government revenue in a Romer-style endogenous growth model. Lower tax rates on financial income (returns to physical capital and intellectual property) do increase the tax base in this environment, but not enough to expand revenue from this tax alone. Lower financial income taxes stimulate innovation and enhance labor productivity in the long run. For plausible parameter values, this generates higher overall tax revenue for the government in response to a reduction in the financial income tax rate. The analysis reveals the dynamics of the economy to be very sluggish and for some variables non-monotonic. Halflives for many variables are on the order of decades, rather than years.
\end{abstract}

*Contact: Dean Scrimgeour, Economics Department, Colgate University, 13 Oak Drive, Hamilton, NY 13346. Email: dscrimgeour@colgate.edu. Thanks to Lewis Davis, Chad Jones, Lorenz Kueng, Viktor Tsyrennikov, Philippe Wingender, and seminar participants at Carleton University and Colgate University for comments. 


\section{Introduction}

Policymakers who want to change the tax rates that apply to capital income and wages must consider the effects that this will have on overall revenues. Traditional approaches to estimating the revenue effects of tax rate changes focused on static behavioral responses - essentially the short-run response of labor and capital income to a change in the tax rate. ${ }^{1}$ Fullerton (1982) discusses whether labor income tax reductions might induce expansions of tax revenue, arguing that such Laffer curve effects (higher government revenue at lower tax rates) are unlikely due to low labor supply elasticities. Malcomson (1986) studies the same question and emphasizes the relevance of general equilibrium effects.

In spite of skepticism about the short-run revenue enhancing effects of tax cuts in the 1980s, recent studies have considered the possibility that the longrun effect of a tax cut is to expand the government's tax collection. Economic research has generally been skeptical of large short-run behavioral responses to tax rate changes. By contrast, more economists believe that long-run responses of labor supply and especially of capital supply may be large, potentially justifying lower tax rates. ${ }^{2}$ As Mankiw and Weinzierl (2006) point out in the context of the Ramsey model, the accumulation of capital means that a lower tax rate on capital will ultimately increase the tax base, limiting the long-run reduction in revenues from a tax rate reduction. Auerbach (1996) gives a general presentation of issues related to dynamic scoring. See also Auerbach and Kotlikoff (1987) who study a wide range of issues related to dynamic aspects of fiscal policy.

A number of other studies have considered the dynamic effects of taxes on government revenue in endogenous growth models. Those who have used $A K$ models to explore the effects of taxes include Stokey and Rebelo (1995); Agell and Persson (2001); Ireland (1994); Bruce and Turnovsky (1999). The results of the $A K$ model are fairly straightforward to develop. Production is proportional to capital, $Y=A K$, though individuals may perceive this production function

\footnotetext{
${ }^{1}$ This issue gained prominence in the early 1980s when some claimed that the United States had tax rates so high that lower tax rates would increase tax revenue. This hypothetical situation was known as being on the wrong side of the Laffer Curve.

${ }^{2}$ A notable counterexample is Goolsbee (2000) who argues that a reduction in high-income tax rates had large short-run effects but small long-run effects.
} 
to be $Y=\tilde{A} K^{\alpha} L^{1-\alpha}$. Absent depreciation, the real interest rate is $r=\alpha A$. The growth rate of the economy is determined from the consumption Euler equation: $\dot{C} / C=\sigma\left(\left(1-\tau_{v}\right) \alpha A-\rho\right)$, where $\sigma$ is the intertemporal elasticity of substitution, $\rho$ is the discount rate, and $\tau_{v}$ is the tax rate on capital income. As the tax rate on capital income $\tau_{v}$ falls the steady-state growth rate of the economy increases. Tax cuts therefore tradeoff current revenue losses for future revenue gains.

In the $A K$ model above, the optimal growth rate exceeds the growth rate in the decentralized allocation. As such, the appropriate policy is to subsidize capital income, rather than taxing it. It is natural to think that lower taxes (at least when such taxes are positive) would expand the tax base.

Others have used models in which growth is driven by the accumulation of human capital, as in Lucas (1988). Examples include Novales and Ruiz (2002); Pecorino (1995); De Hek (2006); Milesi-Ferretti (1998); Milesi-Ferretti and Roubini (1998); Hendricks (1999). While some find that lower tax rates provide extensive stimulus to the economy, others report more modest responses. For example, Hendricks (1999) presents a life-cycle model with human capital accumulation. In his model human capital accumulation drives the economy in the long run, but lower tax rates do not generate large increases in the scale of the economy.

Another strand of the literature on the effects of taxation discusses the uses of government revenue. For example, Jones et al. $(1993,1997)$ modify the classic Chamley (1986) and Judd (1985) result that the optimal tax rate on capital income is zero. In their model the government uses tax revenue to provide productive public goods. Cutting taxes means having to cut public services, which may reduce output. Ferede (2008) follows a similar approach. In these papers, a reduction in the tax rate may not be followed by large increases in the tax base since the government has to reduce its investments in public infrastructure. For example, while Mankiw and Weinzierl find that $50 \%$ of a tax cut on capital income is self-financing, Ferede concludes that only $6 \%$ of the tax cut would be self-financing if the tax cut meant the government had to cut back on productive spending.

The $A K$ model as described above relies on large spillovers from using capital to generate endogenous growth through capital accumulation as well as being consistent with facts about the share of income paid to capital. Furthermore, em- 
pirical evidence on the effect of the size of government on the economy's growth rate argues against such strong scale effects (Easterly and Rebelo (1993); Mendoza et al. (1997); Jones (1995b)). While this may be consistent with appropriately parametrized $A K$ models, as in Stokey and Rebelo (1995), it is also consistent with the model I present in which tax rates do not affect the steady-state growth rate of the economy, but may affect the steady-state level of activity.

This paper presents new results on the short-run and long-run effects of taxes in an endogenous growth model. The model is a version of Romer (1990), with growth driven by the production of new designs for capital goods. The model is designed to be consistent with long-run balanced growth with population growth. It is a second generation endogenous growth model in which scale effects are present in the level of activity rather than the growth rate of activity, as emphasized by Jones (1995b). Government policies, such as the tax rate on capital income, do not affect the growth rate, but do affect the level of output and tax revenue. I focus on the issue of how a tax rate reduction affects government revenue. The taxation of returns to accumulated factors does not distinguish between physical capital and knowledge.

This paper adds to the growing literature on the dynamic revenue response to tax rate changes by embedding the policymaker in an endogenously growing economy as modelled by Romer (1990) and Jones (1995a). In this kind of model, the long-run growth rate and level of economic activity are determined in part by the deliberate actions of entrepreneurs and engineers who develop new products and techniques. The extent of innovation is driven by the returns to innovation, and these may be influenced by the supply of capital and labor. Therefore, taxes on these factors may have additional effects on economic activity through this innovation channel.

I will argue that lower taxes on financial income can induce large increases in government revenue. In the short run, lower tax rates for financial income reduce government revenue, and the financial income tax base only expands modestly, even in the long run. Since the innovative sector expands labor productivity, and hence labor income tax revenue, eventually increases substantially. In this setting, it is crucial to consider general equilibrium effects and also to distinguish between short-run and long-run outcomes. 
The paper proceeds as follows. Section 2 presents the Romer-style model with taxes on capital income and discusses the steady-state and transition dynamics in this model. Section 3 presents comparative dynamic responses of tax revenue to tax rates. Section 4 concludes.

\section{The Romer Model with Income Taxes}

\subsection{The Economic Environment and Agents}

The economic environment consists of three production sectors. Final goods are produced using durable intermediate goods and labor. The intermediate goods are produced using final output (in the form of capital) and designs. These designs come from the research and development sector, which uses labor and previously developed designs in production, though existing designs used in the $R \& D$ sector are not compensated in the decentralized allocation considered here.

The production of new designs used for making intermediate goods proceeds according to

$$
\dot{A}_{t}=\nu A_{t}^{\phi} L_{A t}^{\lambda}, \quad \phi<1, \lambda>0, A_{0}>0, \nu>0
$$

The intermediate goods sector uses capital together with designs to produce differentiated intermediate inputs. One unit of capital produces one unit of the intermediate good. Each intermediate goods producer owns the design used in production. The measure of designs is $A_{t}$. Total production of intermediate goods is determined by the size of the capital stock:

$$
\int_{0}^{A_{t}} x_{i t} d i=K_{t}
$$

Final output, which can be consumed or transformed into capital, is produced with intermediate inputs and labor

$$
Y_{t}=\left(\int_{0}^{A_{t}} x_{i t}^{\theta} d i\right)^{\alpha / \theta} L_{Y t}^{1-\alpha}
$$

The decentralized equilibrium in this economy features solutions to the fol- 
lowing problems.

Household Problem. The household problem is to choose time paths of $c_{t}$ (consumption) and $v_{t}$ (financial assets) that maximize

$$
\int_{0}^{\infty} e^{-(\rho-n) t} \frac{c_{t}^{1-1 / \sigma}-1}{1-1 / \sigma} d t
$$

taking the full time series of prices and taxes as given, and subject to the following constraints

$$
\begin{array}{r}
\dot{v}_{t}=\left(\left(1-\tau_{v}\right) r_{t}-n\right) v_{t}+\left(1-\tau_{w}\right) w_{t}-c_{t}+t r_{t}, \quad v_{0}>0 \\
\lim _{t \rightarrow \infty} v_{t} \exp \left\{-\int_{0}^{t}\left(\left(1-\tau_{v}\right) r_{s}-n\right) d s\right\} \geq 0 \quad N P G
\end{array}
$$

where $v$ is assets per person, $c$ is consumption per person, $w$ is the wage rate, $r$ is the pre-tax return on assets, $\rho$ discounts future utility, $n$ is the growth rate of population, $\tau_{w}$ is the labor income tax rate, and $\tau_{v}$ is the tax rate for asset income. ${ }^{3}$

Final Goods Problem. The final goods sector is perfectly competitive. At each point in time, firms demand labor and intermediate goods, taking wages and intermediate goods prices as given, to maximize

$$
\left(\int_{0}^{A_{t}} x_{i t}^{\theta} d i\right)^{\alpha / \theta} L_{Y t}^{1-\alpha}-w_{t} L_{Y t}-\int_{0}^{A_{t}} p_{i t} x_{i t} d i
$$

Intermediate Goods Problem. Patent-holding firms in the intermediate goods sector choose a price $p_{i t}$ and quantity to produce to maximize profits

$$
x\left(p_{i t}\right)\left(p_{i t}-r_{t}-\delta\right)
$$

Research and Development Problem. Firms in the R\&D sector produce new designs that intermediate goods firms use to produce new intermediate inputs. There is free entry in this sector, but there are externalities. Firms perceive a constant returns to scale production function, ignoring diminishing returns to labor at the aggregate level in this sector. Increases in activity $\left(L_{A}\right)$ generate something

\footnotetext{
${ }^{3}$ I abstract from a menu of taxes that includes taxes on consumption. Without a labor-leisure choice or home production consumption taxes do not distort allocations.
} 
akin to congestion effects, lowering the marginal product of labor. Firms sell their patented designs for price $P_{A t}$. They demand labor, paid at the economy-wide wage rate $w_{t}$, maximizing profits

$$
P_{A t} \bar{\nu}_{t} L_{A t}-w_{t} L_{A t}
$$

where $\bar{\nu}=A^{\phi} L_{A}^{\lambda-1}$.

Government Budget. The government simply collects taxes and returns them to households lump sum. In per capita terms, the government budget constraint is:

$$
t r_{t}=\tau_{v} r_{t} v_{t}+\tau_{w} w_{t}
$$

The government uses two tax instruments: a linear tax on labor income and a linear tax on non-labor income which is derived from two forms of assets, physical capital and intellectual capital. In this model there is neither government consumption nor public goods provision. (See Barro (1990); Jones et al. (1993); Ferede (2008) and others for models where the government can provide productive public goods.) Households are Ricardian, so the timing of tax rebates is irrelevant to the households' decisions. Assuming the government rebates all revenues immediately means that we do not have to keep track of the government's asset position.

\subsection{Definition of Equilibrium}

The decentralized equilibrium in this Romer economy with taxes is a time path for quantities $\left\{c_{t}, L_{Y t}, L_{A t}, L_{t}, A_{t}, K_{t}, Y_{t}, v_{t},\left\{\pi_{i t}\right\}_{i=0}^{A_{t}},\left\{x_{i t}\right\}_{i=0}^{A_{t}}, \bar{\nu}_{t}, t r_{t}\right\}_{t=0}^{\infty}$ and prices $\left\{P_{A t},\left\{p_{i t}\right\}_{i=0}^{A_{t}}, w_{t}, r_{t}\right\}_{t=0}^{\infty}$ such that for all $t$ :

1. $c_{t}, v_{t}$ solve the household problem

2. $\left\{x_{i t}\right\}_{i=0}^{A_{t}}$ and $L_{Y t}$ solve the final goods firm problem

3. $\left\{p_{i t}\right\}_{i=0}^{A_{t}}$ and $\left\{\pi_{i t}\right\}_{i=0}^{A_{t}}$ solve the intermediate goods firm problem

4. $L_{A t}$ solves the research and development firm problem

5. $Y_{t}=\left(\int_{0}^{A_{t}} x_{i t}^{\theta} d i\right)^{\alpha / \theta} L_{Y t}^{1-\alpha}$ 
6. $A_{t}$ follows from equation (1)

7. $K_{t}$ satisfies $\int_{0}^{A_{t}} x_{i t} d i=K_{t}$

8. $\bar{\nu}_{t}$ satisfies the ideas production function: $\bar{\nu}_{t}=A_{t}^{\phi} L_{A t}^{\lambda-1}$

9. Asset arbitrage: $r_{t}=\frac{\pi_{i t}}{P_{A t}}+\frac{\dot{P}_{A t}}{P_{A t}}$

10. $r_{t}$ clears the capital market: $v_{t} L_{t}=K_{t}+P_{A t} A_{t}$

11. $w_{t}$ clears the labor market: $L_{Y t}+L_{A t}=L_{t}$

12. $L_{t}=L_{0} e^{n t}$

13. $t r_{t}$ satisfies the government budget constraint: $t r_{t}=\tau_{v} r_{t} v_{t}+\tau_{w} w_{t}$

Note that households are taxed on their financial income, derived from either physical capital $(K)$ or intellectual property $(A)$. Asset arbitrage implies that the returns to investing a dollar in each asset class be the same. This is condition (9) in the definition of equilibrium above. In the presence of taxes, this condition implies that capital gains from appreciating prices of intellectual property are taxed. If only profits were taxed, the arbitrage equation would be:

$$
\left(1-\tau_{v}\right) r_{t}=\left(1-\tau_{v}\right) \frac{\pi_{i t}}{P_{A t}}+\frac{\dot{P_{A t}}}{P_{A t}},
$$

and this would have different implications for the steady-state price of patented ideas. In fact, it is possible to show that in the absence of depreciation, or if income from physical capital is taxed without allowing for depreciation, a policy that taxes only dividend payments and not capital gains of patented technologies makes the composition of the capital stock (i.e., the share of the overall capital stock that is physical capital distinct from intellectual property) invariant to the capital income tax rate.

\subsection{Balanced Growth Path}

This section presents some properties of the balanced growth path for the economy. Consider first static aspects of the equilibrium allocation. Each intermediate 
goods producer faces the same problem, so they will produce the same quantity $x$ and sell it for the same price $p$. The profit $\pi$ for each patent holder will be the same and all patents will trade at the same price $P_{A}$. Since the entire capital stock is divided among the intermediate goods producers, we find that

$$
x_{i t}=x_{t}=\frac{K_{t}}{A_{t}}
$$

and the price charged is a markup over marginal cost

$$
p_{i t}=p_{t}=\frac{1}{\theta}\left(r_{t}+\delta\right)
$$

so that the profit for each firm is

$$
\pi_{i t}=\pi_{t}=\frac{1-\theta}{\theta}\left(r_{t}+\delta\right) \frac{K_{t}}{A_{t}}=\alpha(1-\theta) \frac{Y_{t}}{A_{t}} .
$$

Note that $\theta$ relates to the profit share. Specifically, the share of final output (note: not of total income) paid out as pure profits is $\alpha(1-\theta)$. If profits actually represent $10 \%$ of final output and $\alpha$ is one-third, then the appropriate value for $\theta$ would be about 0.7 . The gross markup is $1 / \theta$. So in order to match net markups of $10 \%, \theta$ should be around 0.9 .

As in Jones (1995a), using $g_{z}$ for the growth rate of variable $z$, the steady-state growth rate of $A$ is given by

$$
g_{A}=\frac{\lambda n}{1-\phi}
$$

Since output is equal to

$$
Y_{t}=A_{t}^{\alpha \frac{1-\theta}{\theta}} K_{t}^{\alpha} L_{Y t}^{1-\alpha}
$$

the growth rate of output in steady state is given by

$$
g_{Y}=g_{K}=n+\frac{\alpha}{1-\alpha} \frac{1-\theta}{\theta} g_{A}=\left(1+\frac{\alpha}{1-\alpha} \frac{1-\theta}{\theta} \frac{\lambda}{1-\phi}\right) n
$$

so that the growth rate of output and capital in steady state depends only on structural parameters, not on investment rates or tax rates. ${ }^{4}$ From the capital ac-

\footnotetext{
${ }^{4}$ This is the distinguishing feature of semi-endogenous growth models. By contrast, first gen-
} 
cumulation equation $\left(\dot{K}_{t}=Y_{t}-C_{t}-\delta K_{t}\right)$ we know that consumption grows at the same rate as output and capital in steady state. Therefore, the consumption Euler equation determines the steady-state interest rate: from the household problem, the growth rate of consumption is

$$
\begin{aligned}
\dot{c}_{t} / c_{t} & =\sigma\left(\left(1-\tau_{v}\right) r_{t}-\rho\right) \\
& \rightarrow g_{Y}-n \\
\Rightarrow r^{*} & =\frac{\frac{\alpha}{1-\alpha} \frac{1-\theta}{\theta} \frac{g_{A}}{\sigma}+\rho}{1-\tau_{v}}
\end{aligned}
$$

Financial income taxes do not affect the long-run growth rate of consumption. Higher tax rates raise the steady-state return to assets the household owns. Since the marginal product of capital is decreasing in the amount of capital, this means that the steady-state capital stock is lower. The stock of knowledge is also lower in a steady state with higher capital income taxes.

The fraction of labor allocated to the research and development sector is consistent with integrated labor markets. The wage paid to researchers is equal to the wage received by laborers producing final output. Therefore,

$$
P_{A t} \frac{\dot{A}_{t}}{L_{A t}}=(1-\alpha) \frac{Y_{t}}{L_{Y t}}
$$

which implies that

$$
\frac{s_{A t}}{1-s_{A t}}=\frac{P_{A t} \dot{A}_{t}}{(1-\alpha) Y_{t}}
$$

On the balanced growth path, asset arbitrage requires $P_{A t}=\frac{\pi_{t}}{r^{*}-g_{P_{A}}}$, where $g_{P_{A}}=$ $g_{\pi}=g_{Y}-g_{A}$. Consequently

$$
\frac{s_{A}^{*}}{1-s_{A}^{*}}=\frac{\alpha(1-\theta) g_{A}}{(1-\alpha)\left(r^{*}-\left(g_{Y}-g_{A}\right)\right)} \equiv \psi^{*}
$$

eration endogenous growth models (Romer (1990); Grossman and Helpman (1991); Aghion and Howitt (1992)) have strong scale effects so that the growth rate may be influenced by tax rates. See Jones (1999) and Jones (2005) for more on this point. 
The steady-state share of labor allocated to research and development is

$$
s_{A}^{*}=\frac{\psi^{*}}{1+\psi^{*}}=\frac{\alpha(1-\theta) g_{A}}{(1-\alpha)\left(r^{*}-\left(g_{Y}-g_{A}\right)\right)+\alpha(1-\theta) g_{A}} .
$$

Of the terms in this equation, only the steady-state interest rate depends on the tax rate applied to capital income. Intuitively, since higher interest rates reduce the present value of future profits resulting from innovation, they reduce the price of a patented idea. Lower prices for patents discourage the research and development required to develop new ideas. Alternatively, higher tax rates cause less capital to be accumulated, raising its marginal product and therefore the interest rate. It follows that the share of labor working in R\&D is lower the higher is the tax rate $\tau_{v}$. As a result, the stock of knowledge is affected by $\tau_{v}$.

The production function for new ideas shows that on the balanced growth path

$$
A_{t}^{*}=\left[\frac{\nu L_{t}^{\lambda} s_{A}^{* \lambda}}{g_{A}}\right]^{\frac{1}{1-\phi}} .
$$

Higher financial income taxes raise the interest rate and lower the fraction of workers producing new ideas. Therefore the balanced growth path stock of ideas is lower when tax rates are higher.

Along a balanced growth path, capital and output are equal to

$$
\begin{aligned}
\left(\frac{K}{Y}\right)^{*} & =\frac{\alpha \theta}{r^{*}+\delta} \\
Y_{t}^{*} & =A_{t}^{* \frac{\alpha}{1-\alpha} \frac{1-\theta}{\theta}}\left(\frac{K}{Y}\right)^{* \frac{\alpha}{1-\alpha}}\left(1-s_{A}^{*}\right) L_{t} \\
K_{t}^{*} & =\left(\frac{K}{Y}\right)^{*} Y_{t} \\
& =A_{t}^{* \frac{\alpha}{1-\alpha} \frac{1-\theta}{\theta}}\left(\frac{K}{Y}\right)^{* \frac{1}{1-\alpha}}\left(1-s_{A}^{*}\right) L_{t} .
\end{aligned}
$$

Increases in the financial income tax rate lower $A$ and $K / Y$ but increase the fraction of workers producing physical output, so there are competing effects of $\tau_{v}$ on output. This mirrors the relationship between the optimal and equilibrium allocations in the Romer model. For some parametrizations the equilibrium in- 
volves overinvestment in $\mathrm{R} \& \mathrm{D}$, while in others there is too little $\mathrm{R} \& \mathrm{D}\left(s_{A}\right.$ is too small). ${ }^{5}$ If their effect through labor market channels is strong enough, higher financial income taxes could actually increase the size of the stock of physical capital, though this requires unlikely parameter values.

The stock of assets includes both physical capital and patented ideas. The total value of these assets on the balanced growth path is

$$
\begin{aligned}
V_{t}^{*} & =K_{t}^{*}+P_{A t}^{*} A_{t}^{*} \\
& =\left(\frac{\alpha \theta}{r^{*}+\delta}+\frac{\alpha(1-\theta)}{r^{*}-g_{P_{A}}}\right) Y_{t}^{*}
\end{aligned}
$$

so that the share of assets in the form of physical capital (versus patented ideas) depends on the steady state interest rate, which in turn depends on the tax rate on capital income. ${ }^{6}$

Since the value of innovations in the R\&D sector are paid out to researchers as wages, changes in the allocation of labor and of the price of new ideas can affect the labor share of income. Note that total income in this model is $Y+P_{A} \dot{A}$. Payments to labor are $w L=(1-\alpha) Y+P_{A} \dot{A}$. A reduction in the tax rate on capital income lowers the real interest rate and raises the value of output in the R\&D sector relative to the final goods sector. This in turn means the the labor share of income rises.

Tax revenue for the government is $\tau_{v} r^{*} V^{*}+\tau_{w} w^{*} L$. Since there are two taxes, there are two tax bases. The financial income tax base is $r^{*} V^{*}$ while the labor income tax base is $w^{*} L$. The Laffer conjecture is that a reduction in the tax rate

\footnotetext{
${ }^{5}$ For more, see Jones and Williams $(1998,2000)$ for a discussion of the social returns to R\&D. Those papers discuss a related model that also includes a creative destruction distortion. Jones (2005) shows how the socially optimal rates of investment relate to the decentralized allocation's rates of investment in a model that does not have the creative destruction distortion.

${ }^{6}$ If $\delta=0$ and $\alpha=\theta$, then $V_{t}^{*}=\alpha \frac{Y_{t}^{*}}{r^{*}}\left(\frac{r^{*}-\alpha n}{r^{*}-n}\right)$. In that case the asset structure of the economy depends on the growth rate of population and on the steady-state interest rate, which may respond to $\tau_{v}$. Assuming there is no population growth, the share of assets that are physical capital is $\alpha$, independent of $\tau_{v}$. More generally, the effect of population growth on the composition of assets depends on other parameters in the model. If $\alpha=\theta$, then higher $n$ causes the growth rate of the price of an idea to be higher. This lowers the current price of a new idea and means more of the stock of assets will be physical capital. If $\alpha<\theta<1$ and $\lambda>1-\phi$, entirely plausible values, it is possible for this effect to be reversed. For some such combinations of parameters higher population growth lowers the growth rate of the price of an idea, increasing its current price and the extent of investment in R\&D.
} 
will cause the tax base to increase so much that the product of the two (revenue) increases. Here we have two tax bases. The analysis reveals that the financial income tax base does rise in response to a lower tax rate, but not enough to generate revenue gains. Considering the labor income tax revenue as well leads to the conclusion that lower financial income tax rates can increase total revenue in the long run.

\subsection{Transition Dynamics}

This section discusses transition dynamics for a log-linearized version of the economy. This forms the basis for the comparative dynamics exercises in section 3.. More details are provided in the appendix. I log-linearize the model as follows. Define the vector $\gamma$ as

$$
\gamma_{t}=\left(\begin{array}{c}
\gamma_{1 t} \\
\gamma_{2 t} \\
\gamma_{3 t} \\
\gamma_{4 t}
\end{array}\right) \equiv\left(\begin{array}{c}
\log \left(C_{t} / K_{t}\right) \\
\log \left(\bar{Y}_{t} / K_{t}\right) \\
\log \left(s_{A t}\right) \\
\log \left(\overline{\dot{A}}_{t} / A_{t}\right)
\end{array}\right)
$$

where $\bar{Y}$ is the maximum output that could be obtained at a point in time, based on setting $s_{A}$ equal to zero, and $\overline{\dot{A}}$ is the maximum rate of change of $A$ that is possible at a point in time, based on setting $s_{A}$ equal to one. ${ }^{7}$ Therefore,

$$
Y_{t}=A_{t}^{\alpha \frac{1-\theta}{\theta}} K_{t}^{\alpha} L_{t}^{1-\alpha}\left(1-s_{A t}\right)^{1-\alpha}=\bar{Y}_{t}\left(1-s_{A t}\right)^{1-\alpha}
$$

\footnotetext{
${ }^{7}$ Arnold (2006) analyzes the dynamics of this model with $\lambda=1$. He reduces the model to a similar set of variables as I do here. The main differences are that one of his variables corresponds roughly to $P_{A}$ rather than $s_{A}$ and the variable that represents the output-capital ratio in his paper uses actual output rather than maximum output. I prefer to use maximum output so that this variable is a genuine state variable and is unable to jump. With my set-up there are two obvious state variables and two control variables that correspond to the two key allocation decisions in the model: to consume or invest, and to produce final output or to produce ideas. See also Schmidt (2003) for another discussion of transition dynamics in the Romer model.
} 
and

$$
\overline{\dot{A}}_{t}=\nu A_{t}^{\phi} L_{t}^{\lambda}=\dot{A}_{t} s_{A t}^{-\lambda}
$$

The limiting values of these variables are determined as follows. Equation (16) determines the steady-state value $\gamma_{3}^{*}$. Then $\gamma_{4}^{*}$ is equal to $\log \left(g_{A}\left(s_{A}^{*}\right)^{-\lambda}\right)$. The steady-state interest rate in equation (12) determines the steady-state capital output ratio, which combined with $s_{A}^{*}$ determines $\gamma_{2}^{*}$. Finally, $C / K=Y / K-\dot{K} / K-\delta$ which determines $\gamma_{1}^{*}$.

It is convenient to work with these four variables since they are each constant on a balanced growth path. Two correspond roughly to the state variables in the model ( $\gamma_{4}$ relates to the stock of knowledge, $\gamma_{2}$ to the capital stock), and do not jump. By contrast, the other two correspond to control variables ( $\gamma_{1}$ to the investment rate, and $\gamma_{3}$ to the intensity of research and development efforts) and can jump. The dynamics of the four variables are determined by two initial conditions ( $K_{0}$ and $A_{0}$ ) and two endpoint conditions (the limiting behavior of $C$ and $\left.s_{A}\right)$.

The rate of change of $\gamma$ is given by

$$
\dot{\gamma}_{t}=\left(\begin{array}{c}
\dot{\dot{C}}_{t}-\frac{\dot{K_{t}}}{K_{t}} \\
\frac{\dot{Y_{t}}}{\bar{Y}_{t}}-\frac{\dot{K_{t}}}{K_{t}} \\
\frac{s_{\dot{A} t}}{s_{A t}} \\
\lambda \frac{\dot{L}_{t}}{L_{t}}-(1-\phi) \frac{\dot{A}_{t}}{\dot{A}_{t}}
\end{array}\right)
$$

Equations for three elements of this vector are straightforward. The growth rate of consumption is given by the household's Euler equation. The growth rate of the capital stock comes from the capital accumulation equation. The growth rate of the maximum growth rate of $A$ is determined by the growth rate of $A$ and of population. The growth rate of $s_{A t}$ is rather more complicated, and is based on the dynamics of the labor market equilibrium condition in equation (14). This equation implies that the rate of change of $s_{A}$ is influenced by the rate of change of $P_{A}, A, K$, and $L$. If the price of patented ideas is rising over time then, all else equal, the fraction of labor allocated to R\&D will also be rising. The derivation of 
each equation is covered in the appendix.

For all the calibrations I applied, the log-linearized system of equations was characterized by two negative and two positive eigenvalues. This is consistent with there being two state variables ( $K$ and $A$ ) and two jump variables ( $C$ and $s_{A}$ ). Arnold (2006) shows that a slightly simpler version of this model without taxes must have two negative and two positive eigenvalues.

\section{Comparative Dynamics: Response to $\tau_{v}$ Changes}

This section discusses the response of the economy in general and tax revenues in particular when there is a change in the financial income tax rate. It shows the long-run response of tax revenues to tax rates as well as transition paths for a range of variables when there is a change in $\tau_{v}$.

\subsection{Static Response of Tax Revenue}

As a benchmark consider the Ramsey model where the interest rate at a point in time is determined by the capital stock. Factor supplies are inelastic in the shortrun, so the marginal product of capital is a given. The short-run elasticity of tax revenue with respect to the capital income tax rate is equal to one in the Ramsey model (Mankiw and Weinzierl (2006)). This is because the marginal product of capital, which determines the real interest rate, is pinned down by the capital stock, and the capital stock cannot jump.

In the Romer model, the marginal product of capital depends on the allocation of labor between the two sectors. And even if the real interest rate were not to jump in the R\&D model, if the price of a patented idea jumps, then the stock of assets whose income streams are taxed also jumps so that the elasticity of tax revenue with respect to changes in the tax rate need not be one. For some parametrizations, tax revenue jumps less than the percentage of the change in the tax rate, while in other parametrizations it jumps more. In spite of these possibilities, for my calibrations, the elasticity of financial income tax revenue with respect to $\tau_{v}$ is approximately one. 


\subsection{Long-run Response of Tax Revenue}

When thinking about the long-run response of tax revenues to changes in the financial income tax rate, it matters a lot whether we consider the effect on financial income tax revenues or overall tax revenues. Since changes in $\tau_{v}$ affect incentives to innovate, they have long-run effects on labor productivity and wages. So a tax cut for financial income can stimulate labor income tax revenue eventually. In fact, this is precisely what I find.

First consider the effect on revenue from the financial income tax. In the long run, a small number of key parameters affect the response of tax revenue to the tax rate on financial income. First, $\theta$, which governs the substitutability in production of different kinds of capital goods, has a particularly important role. For low values of $\theta$, low tax rates are consistent with high tax revenues, so that a very relevant Laffer curve effect is present. Evidence on the share of income received as pure profits (returns to patents) and on markups suggest that such values of $\theta$ are implausible. For higher values of $\theta$ (closer to 0.9 so that markups are around $10 \%$ ) suggest that tax revenues are maximized at tax rates closer to $85 \% .{ }^{8}$

Figure 1 shows the (log of) steady-state tax revenue as a function of the tax rate for three different values of $\theta .{ }^{9}$ For high values of $\theta$ (for example, $\theta=0.9$, consistent with $10 \%$ markups) the long-run elasticity of output with respect to $A$ is low. Therefore, lower tax rates, while they increase the stock of knowledge and hence output, do not raise government revenue except when starting from extremely high tax rates. For lower values of $\theta$ (such as 0.5 , which would imply markups of $100 \%$ and pure profit shares of $16 \%$ ), tax revenue peaks as a function of the tax rate at relatively moderate tax rates. Such low values of $\theta$ imply that a larger share of income is accrued as pure profits than findings of Basu and Fernald (1997) and Broda and Weinstein (2006) would imply. Parameter values used to generate these figures are reported in Table 1.

Total tax revenue derives from financial income taxes and labor income taxes. Since higher financial income taxes lower productivity, by reducing the extent of

\footnotetext{
${ }^{8}$ By contrast, in the Ramsey model, tax revenues are maximized when $\tau_{v}=1-\alpha$ where $\alpha$ is the elasticity of ouptut with respect to capital.

${ }^{9}$ These are for a particular point in time. On the balanced growth path tax revenue grows at the same rate regardless of the tax rate, so choosing a different point in time would amount to shifting the curves in this graph up or down by some constant amount.
} 
Table 1: Calibrated Values of Model Parameters

\begin{tabular}{ccc}
\hline \hline Parameter & Meaning & Calibrated Value \\
\hline$\alpha$ & Elasticity of Y w.r.t. K & $1 / 3$ \\
$\theta$ & Related to Elasticity of Substitution & 0.7 \\
& between Varieties of Capital & \\
$\delta$ & Depreciation rate for physical capital & 0.05 \\
$\nu$ & Productivity in R\&D & 1 \\
$\lambda$ & Elasticity of $\dot{A}$ w.r.t. $L_{A}$ & 0.7 \\
$\phi$ & Elasticity of $\dot{A}$ w.r.t. $A$ & 0.9 \\
$\rho$ & & \\
$\sigma$ & Discount rate & 0.02 \\
$n$ & Intertemporal elasticity of substitution & 1 \\
& Population growth rate & 0.01 \\
$\tau_{w}$ & & 0.25 \\
\hline \hline
\end{tabular}

innovation, they lower wages and labor income tax revenue. So even if higher financial income tax rates increase financial income tax receipts, they might lower overall tax revenue through the effect on labor markets. Some pertinent results are summarized in Figure 2, which shows that the tendency for total revenues to be higher at low tax rates is most pronounced for implausibly low values of $\theta$. However, even for $\theta=0.7$, the central value in my calibration, lower tax rates tend to increase total revenue.

The subsequent figures, $3 \mathrm{a}$ and $3 \mathrm{~b}$, show steady-state output and consumption as functions of the tax rate, again for different values of $\theta$. Since taxing asset income does not correct the underlying distortions in this economy, higher taxes are always associated with lower output and consumption in the model.

Figures $4 \mathrm{a}$ and $4 \mathrm{~b}$ show how steady-state tax revenue responds to the tax rate 
Figure 1: Steady-State Financial Income Tax Revenue as a Function of $\tau_{v}$

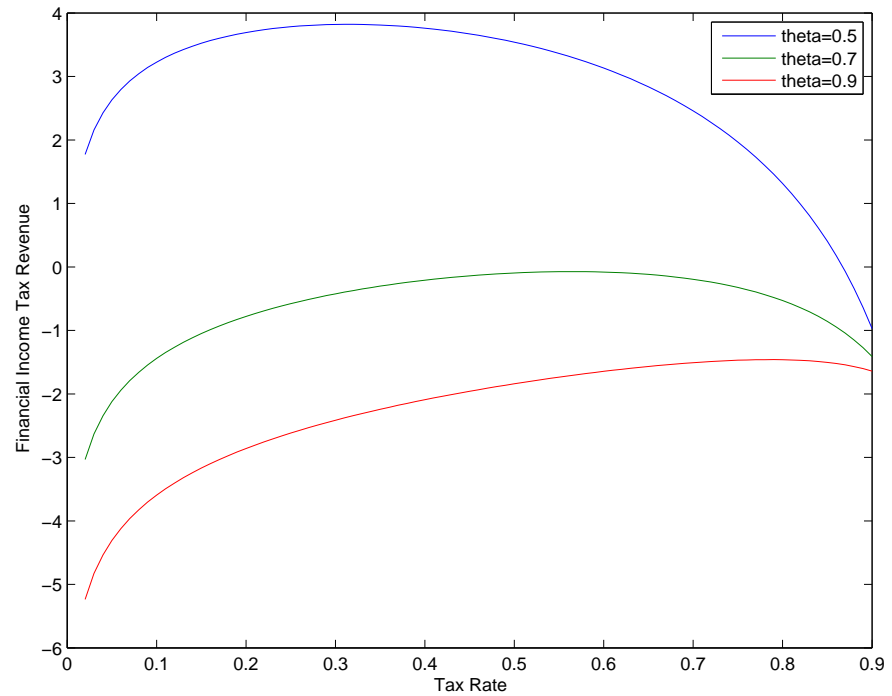


Figure 2: Steady-State Total Tax Revenue as a Function of $\tau_{v}$

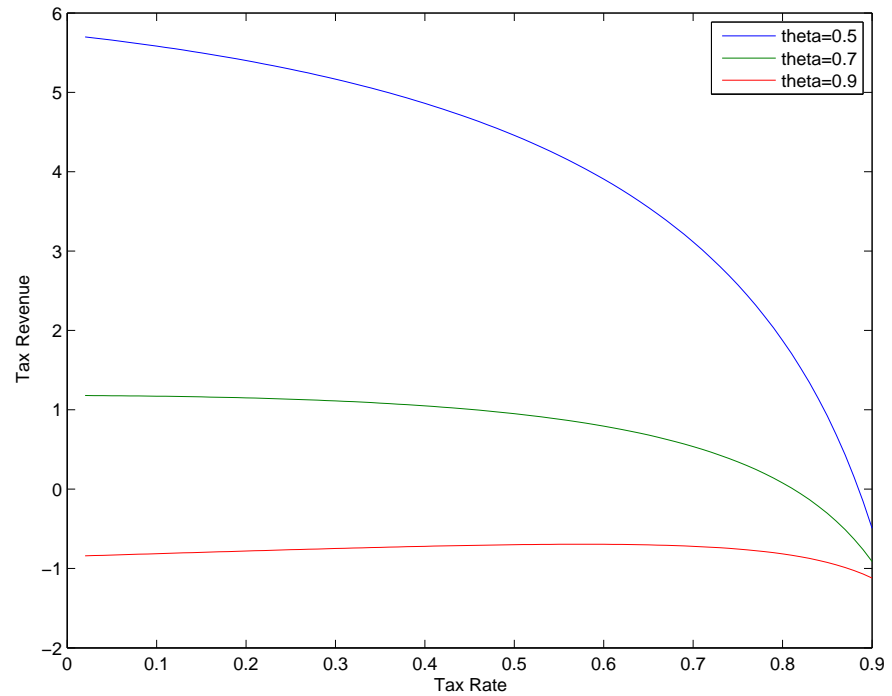


Figure 3: Steady-State Output and Consumption

(a) Output as a Function of $\tau_{v}$

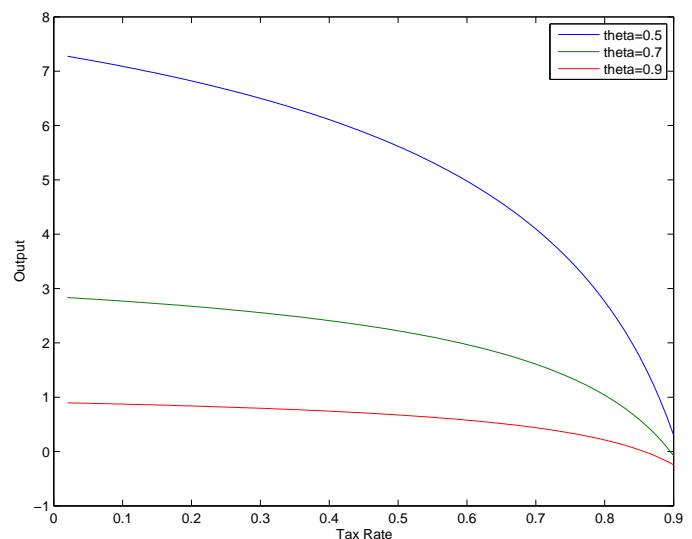

(b) Consumption as a Function of $\tau_{v}$

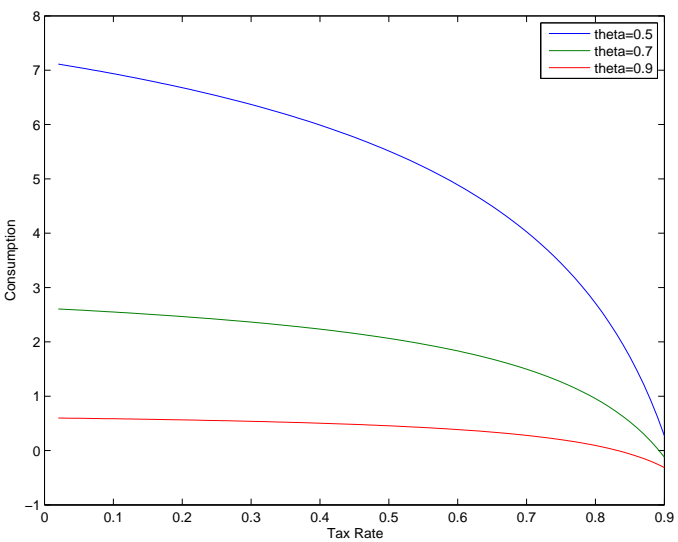

Notes: output and consumption, in logs, along the balanced-growth path; any other time on the balanced-growth path shifts these lines up or down in parallel. 
Figure 4: Steady-State Total Tax Revenue as a Function of $\tau_{v}$
(a) For values of $\phi$
(b) For values of $\lambda$
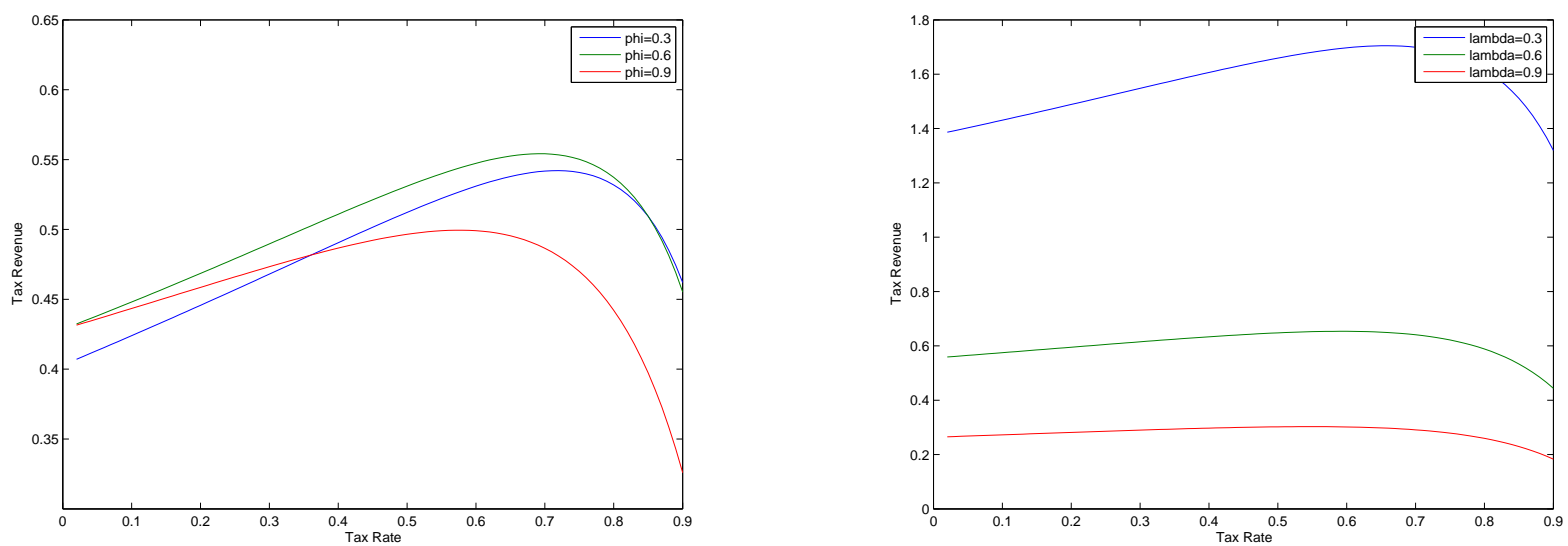

Notes: total tax revenues, in logs, along the balanced-growth path; any other time on the balancedgrowth path shifts these lines up or down in parallel. 
for different values of $\phi$ and $\lambda$. Variation in $\phi$ and $\lambda$ do have some effect on the shape of the tax revenue-tax rate curve. For each value of $\phi$ graphed, the revenue maximizing tax rate is around $60 \%$ to $70 \%$. For different values of $\lambda$ the revenue maximizing tax rates again exceed $50 \%$.

\subsection{Dynamic Response of Tax Revenue}

This section illustrates the response of the economy to a reduction in financial income tax rates from $40 \%$ to $30 \%$ while labor income taxes are maintained at $25 \% .^{10}$ All tax revenue is immediately returned in lump-sum fashion to households. The economy starts on its balanced growth path, then faces a new, permanently lower tax rate. The dynamic response of the economy is computed using the log-linearized version of the model.

Figures 5 and 6 show the responses of the two key allocation choices in the economy, $(\log )$ consumption and the allocation of labor between the two sectors. Initially consumption drops around $10 \%$, but after a seven periods rises to be above the previous balanced growth path, eventually converging to the new steady-state with consumption around $12 \%$ higher than it would have been without the tax reform. This cut in current consumption is a response to the suddenly higher after-tax returns available. Consumers are willing to reduce current consumption because, more than at the higher tax rate, this generates a build-up in the capital stock that advances output.

As for all variables in this model, the convergence of consumption does not occur at a constant rate. Since there are two state variables, there are two eigenvalues that govern the speed of convergence to the steady state. Initially, consumption converges swiftly, with half the gap to the new balanced growth path closed in about ten years. The gap narrows only slightly in the following ten years though. Instead there is a long period of very gradual convergence to the new balanced growth path.

Initially the share working in $R \& D$ jumps up toward the new steady state, but

\footnotetext{
${ }^{10}$ OECD (2011) reports a corporate income tax rate of 39.2\% for the United States (see Table II.1). Exemptions mean that firms typically do not pay a marginal tax rate of $39.2 \%$ to the U.S. government, but the tax does affect their incentives, and there are additional taxes assessed to non-wage income, such as dividend taxation, that should be thought of as included in $\tau_{v}$.
} 
Figure 5: Consumption Response to a Lower Tax Rate

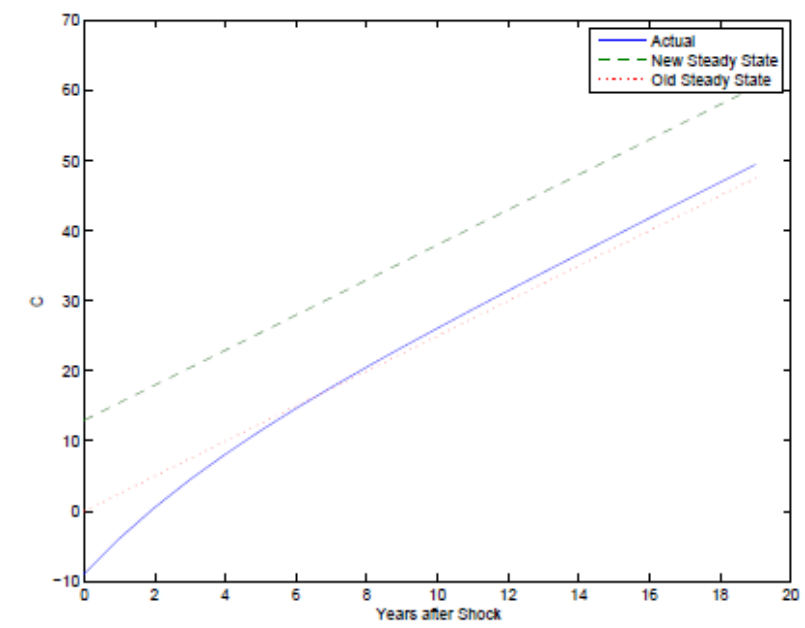

after the jump the share gradually falls before eventually converging to the new steady-state value. Mechanically, the non-monotonic convergence is due to the dynamics of the system being governed by two negative eigenvalues. For $s_{A}$ the signs of the coefficients on the corresponding eigenvectors are opposite, hence the initial drift away from the steady state before convergence.

More intuitively, the dynamics of the labor share are determined by the relative values of the marginal product of labor in final output and in R\&D. At first, when the financial income tax falls, the value of producing new designs increases, so there is a jump in $s_{A}$ toward the R\&D sector. After this jump, there is an expansion of $A$, which increases the incentives to invest in physical capital, which in turn increases the marginal product of labor in final output. Therefore labor migrates back toward the final output sector. The incentives to invest in $K$ slow quickly, but the ongoing accumulation of $A$ gradually increases the value of labor in the R\&D sector, drawing workers back toward that sector.

Figure 7 shows the price of patented inventions jumping up from its initial balanced growth path, though it will eventually converge to a level below its 
Figure 6: Labor Allocation Response to a Lower Tax Rate

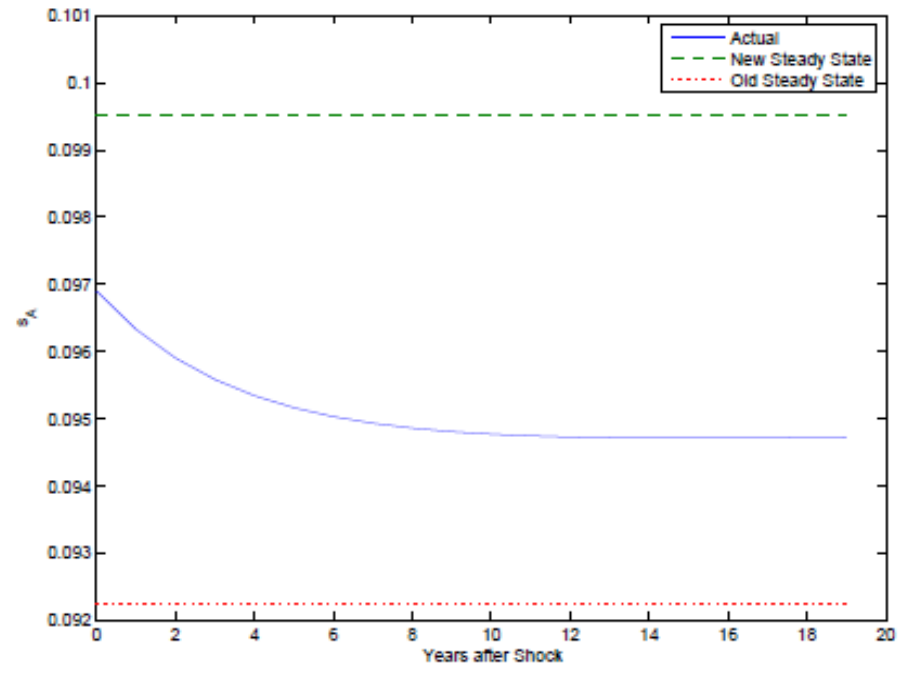

Figure 7: Response of the Price of a Patent to a Lower Tax Rate

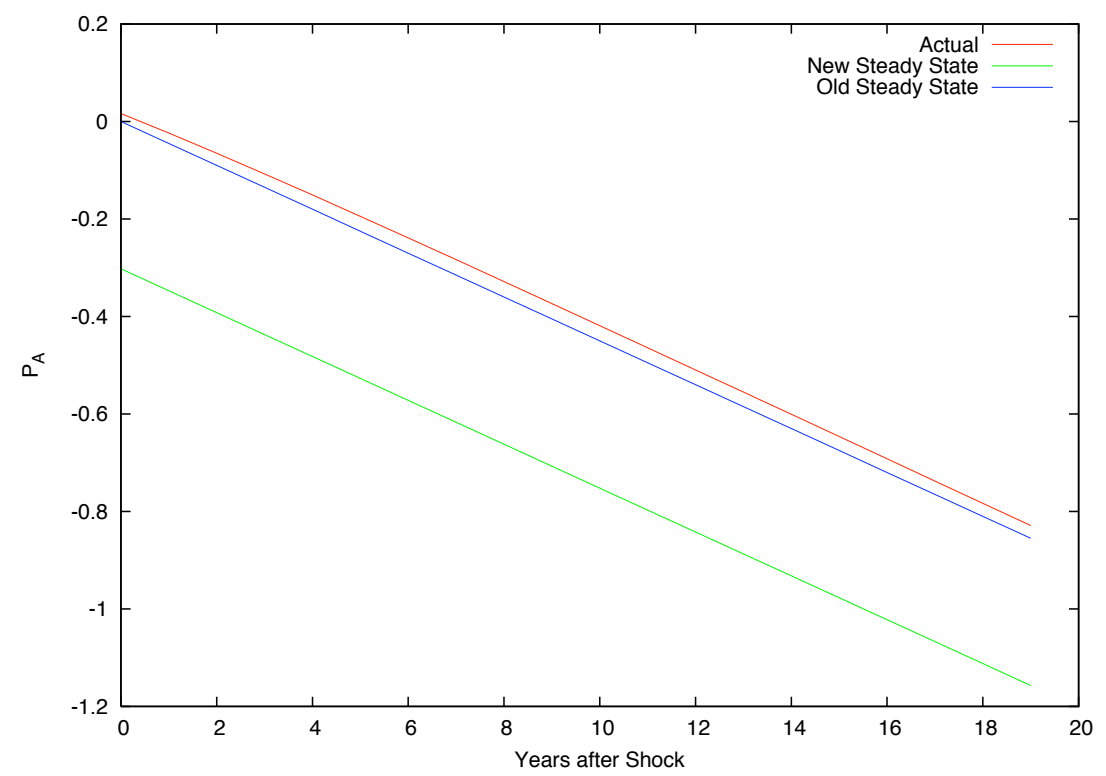


Figure 8: Response of Financial Income Tax Revenue to a Lower Tax Rate

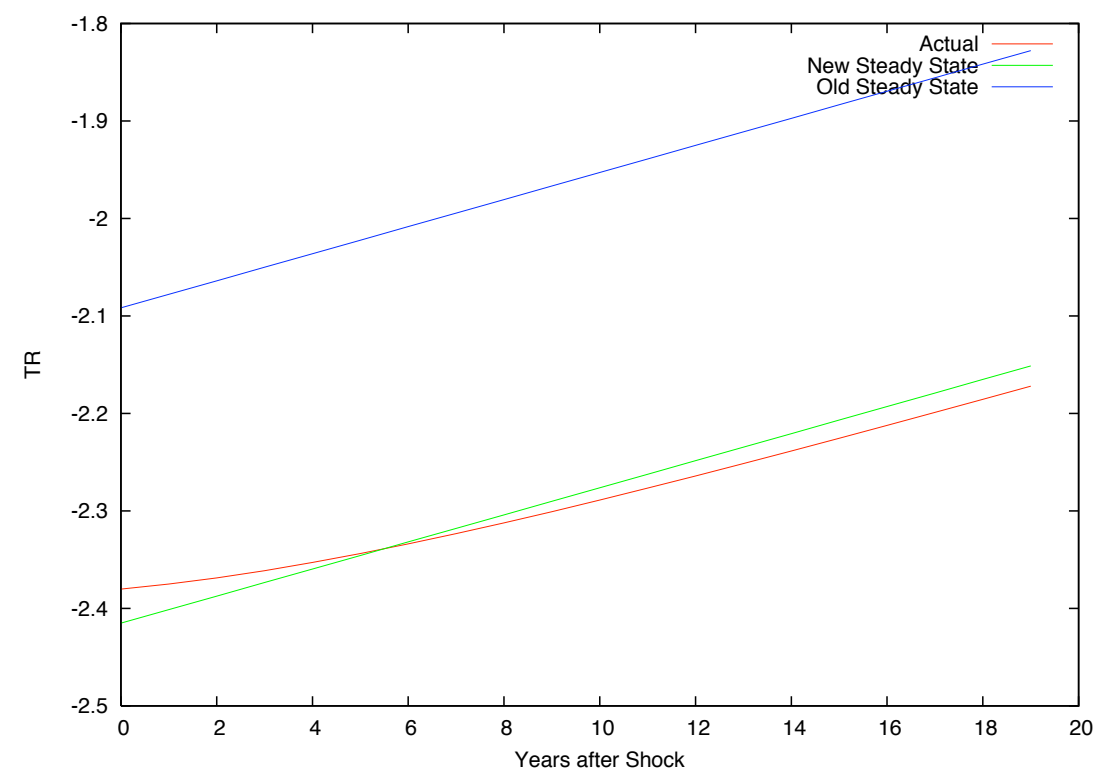

prior trajectory. This graph shows how difficult it could be to infer the effects of a policy change from the data. The asset price jumps up initially and then shrinks at a near constant rate, a rate that is close to its steady state growth rate. As such, an observer could reasonably assess that the policy raised asset prices. However, the graph shows that the eventual effect of the policy is to lower the price of a patented design. The glacial speed of convergence in the model makes it hard to detect the effects of tax policy.

The financial income tax revenue generated for the government falls initially, since the tax rate is reduced. Figure 8 shows that it overshoots the new steady state value. Somewhat surprisingly, it continues to grow more slowly than its steady-state growth rate, dipping further below the new balanced growth path to which it eventually converges. Since the financial income tax base $\left(r_{t} V_{t}\right)$ barely responds in the short run, as in figure 9, the elasticity of financial income tax revenue with respect to the tax rate is approximately one. Initially the tax base grows more slowly than in the long run, which is why the financial income tax revenue also grows slowly at first. Over time the tax base rises, and will eventually be around $8 \%$ higher that without the tax change. This partially offsets having a lower tax rate: tax revenue from this source is around 30\% lower initially, but 
Figure 9: Response of Financial Income Tax Base to a Lower Tax Rate

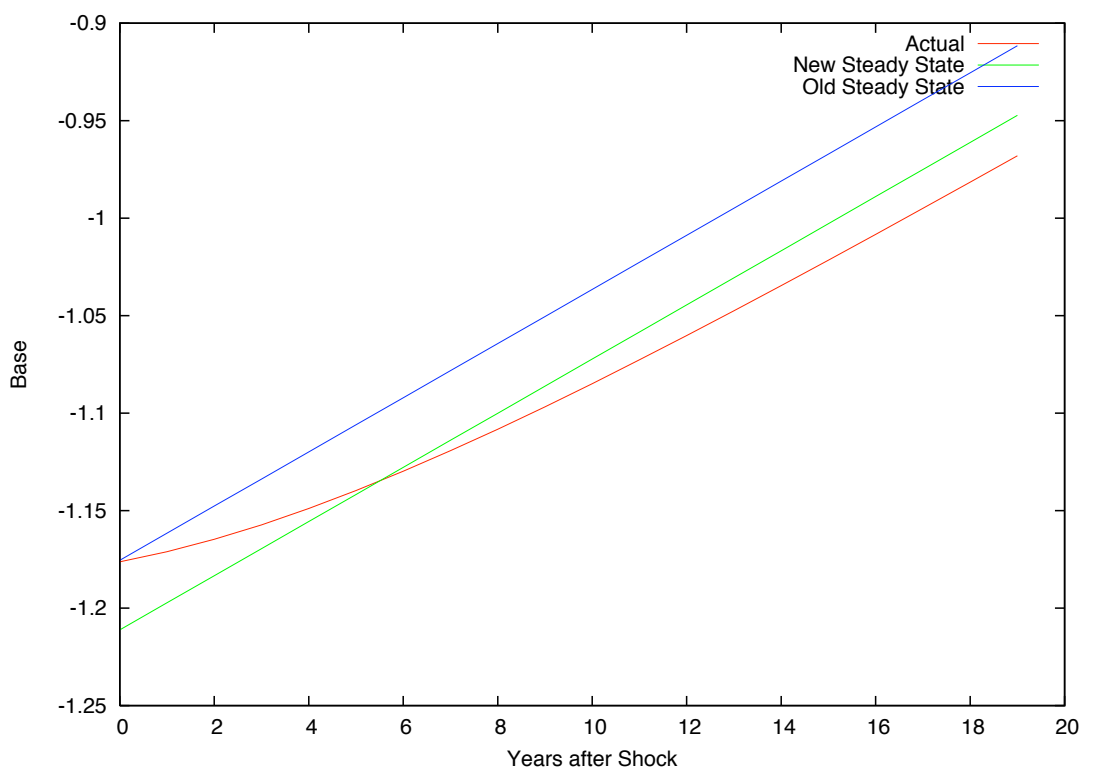

Figure 10: Response of Total Tax Revenue to a Lower Tax Rate

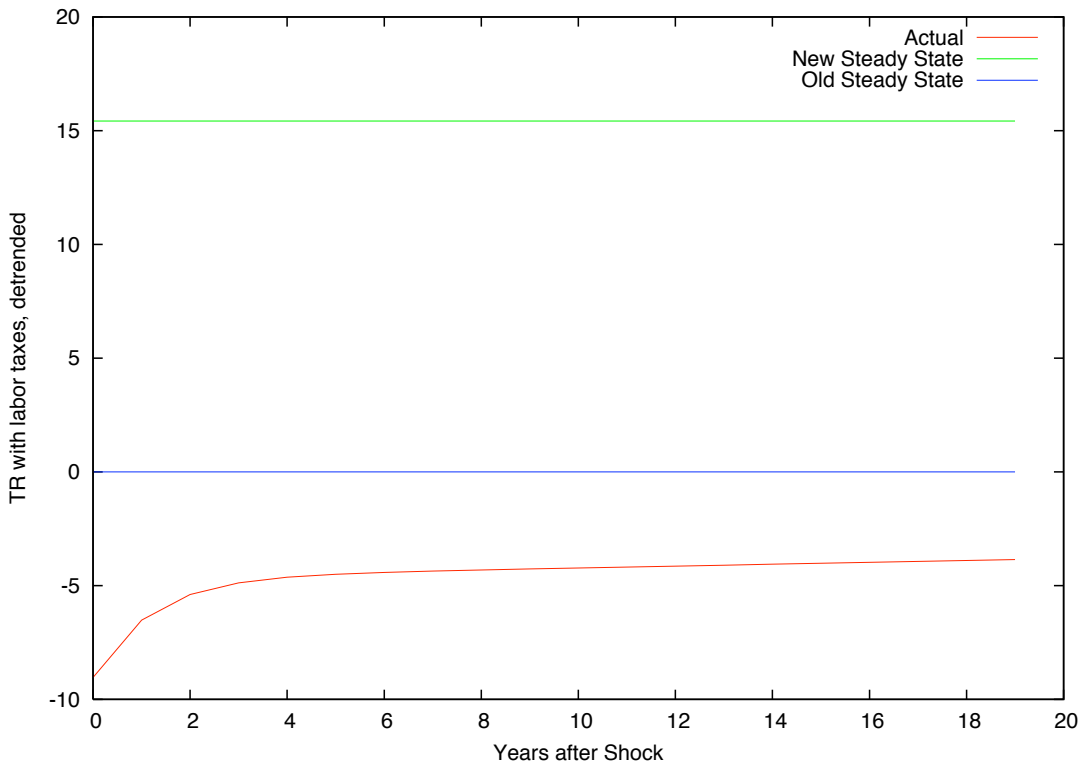


only $22 \%$ lower in the long run.

When we broaden the focus to include labor income tax revenues also we find significant long-run revenue gains from lowering financial income tax rates. Total revenue falls around $8 \%$ in the short run (less than the percentage reduction in financial income tax revenue since labor income taxes provide most of the revenue in this model). Eventually, as indicated by the New Steady State line, total tax revenue will be around $7 \%$ higher than without the tax change. However, these dynamic Laffer curve effects occur so slowly that it is unlikely they could be detected in the data.

\section{Conclusion}

This paper has investigated the dynamic response of tax revenue to changes in the tax rate applied to capital income in a model of endogenous growth through research and development. The model modifies Romer (1990) and Jones (1995a) to incorporate a tax on financial income, defined as income derived as returns to physical capital and intellectual property, and a tax on labor income. The model is log-linearized and the dynamic response of the economy to a tax cut is presented.

For some parameter values, especially for low values of $\theta$, very strong dynamic Laffer curve effects are present. For more conventional parameter values, there are weaker, but still important long-run revenue gains from some reductions in financial income tax rates. The analysis of a reduction in $\tau_{v}$ from $40 \%$ to $30 \%$ shows that expansion of the financial income tax base is moderate so only some of the tax cut is self-financing through that channel. However, general equilibrium effects are important: the extra research and development activity stimulates labor productivity and wages, increasing labor income tax revenue in the long run by more than enough to offset the initial revenue losses.

A prominent result in the dynamic analysis is the speed at which variables converge to the new balanced growth path. In response to the shock (a reduction in the financial income tax rate) the variables in the economy converge to their long-run growth paths slowly, at variable speeds, and in some cases nonmonotonically. The half-lives of some variables are on the order of decades, 
rather than years. For variables that converge more quickly at first, such as consumption, the later convergence slows significantly. This aspect of the model's dynamics makes it plausible that the true effects of such a policy might never be uncovered empirically.

A crucial caveat to interpreting these results is the nature of international spillovers from research and development. The model presented here is a closedeconomy model. It may contain useful insights for a world economy in which fiscal austerity is commonplace. However, what are the effects for a single country raising or lowering financial income taxes when others are not? Answering such questions requires a different model that explicitly captures the fact that only some R\& D occurs domestically and carefully considers how foreign activity affects the domestic economy. An analysis along these lines would clearly come to different quantitative conclusions, and possible to different qualitative conclusions too, but would build on the insights in this paper regarding the incentives of innovators and the sluggishness of the responses to tax rate changes. 


\section{A Appendix: Log-Linearizing the Model}

\section{A1. Rate of Change}

From the household's Euler Equation, we know that

$$
\frac{\dot{C}_{t}}{C_{t}}=\sigma\left(\left(1-\tau_{v}\right) r_{t}-\rho\right)+n
$$

where

$$
\begin{aligned}
r_{t} & =\alpha \theta \frac{Y_{t}}{K_{t}}-\delta \\
& =\alpha \theta \frac{\bar{Y}_{t}}{K_{t}}\left(1-s_{A t}\right)^{1-\alpha}-\delta \\
& =\alpha \theta e^{\gamma_{2 t}}\left(1-e^{\gamma_{3 t}}\right)^{1-\alpha}-\delta
\end{aligned}
$$

The capital accumulation equation is standard and gives

$$
\begin{aligned}
\frac{\dot{K}_{t}}{K_{t}} & =\frac{Y_{t}}{K_{t}}-\frac{C_{t}}{K_{t}}-\delta \\
& =e^{\gamma_{2 t}}\left(1-e^{\gamma_{3 t}}\right)^{1-\alpha}-e^{\gamma_{1 t}}-\delta
\end{aligned}
$$

Therefore,

$$
\dot{\gamma_{1 t}}=\sigma\left(\left(1-\tau_{v}\right)\left(\alpha \theta e^{\gamma_{2 t}}\left(1-e^{\gamma_{3 t}}\right)^{1-\alpha}-\delta\right)-\rho\right)+n-e^{\gamma_{2 t}}\left(1-e^{\gamma_{3 t}}\right)^{1-\alpha}+e^{\gamma_{1 t}}+\delta
$$

The second element of $\gamma$ changes according to the growth rates of $\bar{Y}$ and $K$. Note that maximum output can be written as

$$
\bar{Y}_{t}=A_{t}^{\frac{\alpha}{1-\alpha} \frac{1-\theta}{\theta}}\left(\frac{K_{t}}{\bar{Y}_{t}}\right)^{\frac{\alpha}{1-\alpha}} L_{t}
$$

so the growth rate of $\bar{Y}$ is

$$
\frac{\alpha}{1-\alpha} \frac{1-\theta}{\theta} \frac{\dot{A}_{t}}{A_{t}}+\frac{\alpha}{1-\alpha}\left(\frac{\dot{K}_{t}}{K_{t}}-\frac{\dot{\bar{Y}}_{t}}{\bar{Y}_{t}}\right)+n
$$


This implies that

$$
\begin{aligned}
\dot{\gamma_{2 t}} & =\frac{\alpha}{1-\alpha} \frac{1-\theta}{\theta} \frac{\dot{A}_{t}}{A_{t}}-\frac{\alpha}{1-\alpha}\left(\frac{\dot{K}_{t}}{K_{t}}-\frac{\dot{\bar{Y}}}{\bar{Y}_{t}}\right)+n-\frac{Y_{t}}{K_{t}}+\frac{C_{t}}{K_{t}}+\delta \\
& =\frac{\alpha}{1-\alpha} \frac{1-\theta}{\theta} e^{\lambda \gamma_{3 t}+\gamma_{4 t}}-\frac{\alpha}{1-\alpha} \dot{\gamma_{2 t}}+n-e^{\gamma_{2 t}}\left(1-e^{\gamma_{3 t}}\right)^{1-\alpha}+e^{\gamma_{1 t}}+\delta \\
& =\alpha \frac{1-\theta}{\theta} e^{\lambda \gamma_{3 t}+\gamma_{4 t}}+(1-\alpha)\left(n-e^{\gamma_{2 t}}\left(1-e^{\gamma_{3 t}}\right)^{1-\alpha}+e^{\gamma_{1 t}}+\delta\right)
\end{aligned}
$$

The rate of change of $\gamma_{4}$ is straightforward also.

$$
\begin{aligned}
\dot{\gamma_{4 t}} & =(\phi-1) \frac{\dot{A_{t}}}{A_{t}}+\lambda \frac{\dot{L_{t}}}{\dot{L}_{t}} \\
& =-(1-\phi) e^{\lambda \gamma_{3 t}+\gamma_{4 t}}+\lambda n
\end{aligned}
$$

The rate of change of $\gamma_{3 t}$ is equal to

$$
\begin{aligned}
\dot{\gamma_{3 t}}= & \frac{1}{1-\lambda+\alpha \frac{e^{\gamma_{3 t} t}}{1-e^{\gamma_{3 t}}}}\left(\left(1-\tau_{v}\right)\left(\alpha \theta e^{\gamma_{2 t}}\left(1-e^{\gamma_{3 t}}\right)^{1-\alpha}-\delta\right)-(1-\alpha-\lambda) n\right. \\
& -\alpha\left(e^{\gamma_{2 t}}\left(1-e^{\gamma_{3 t}}\right)^{1-\alpha}-e^{\gamma_{1 t}}-\delta\right) \\
& \left.+e^{\lambda \gamma_{3 t}+\gamma_{4 t}}\left(\phi-\alpha \frac{1-\theta}{\theta}+(1-\theta) \frac{\alpha}{1-\alpha} \frac{1-e^{\gamma_{3 t}}}{e^{\gamma_{3 t}}}\right)\right)
\end{aligned}
$$

\section{A2. Linearization}

Linearize the transition equations above. Evaluate the Jacobian at the steadystate values.

$$
\begin{aligned}
& \frac{\partial \dot{\gamma_{1 t}}}{\partial \gamma_{1 t}}=e^{\gamma_{1 t}} \\
& \frac{\partial \dot{\gamma_{1 t}}}{\partial \gamma_{2 t}}=e^{\gamma_{2 t}}\left(1-e^{\gamma_{3 t}}\right)^{1-\alpha}\left(\alpha \theta \sigma\left(1-\tau_{v}\right)-1\right) \\
& \frac{\partial \dot{\gamma}_{1 t}}{\partial \gamma_{3 t}}=-(1-\alpha) e^{\gamma_{2 t}}\left(1-e^{\gamma_{3 t}}\right)^{1-\alpha}\left(\alpha \theta \sigma\left(1-\tau_{v}\right)-1\right) \frac{e^{\gamma_{3 t}}}{1-e^{\gamma_{3 t}}} \\
& \frac{\partial \dot{\gamma}_{1 t}}{\partial \gamma_{4 t}}=0
\end{aligned}
$$




$$
\begin{aligned}
& \frac{\partial \dot{\gamma_{2 t}}}{\partial \gamma_{1 t}}=(1-\alpha) e^{\gamma_{1 t}} \\
& \frac{\partial \dot{\gamma_{2 t}}}{\partial \gamma_{2 t}}=-(1-\alpha) e^{\gamma_{2 t}}\left(1-e^{\gamma_{3 t}}\right)^{1-\alpha} \\
& \frac{\partial \dot{\gamma_{2 t}}}{\partial \gamma_{3 t}}=\alpha \lambda \frac{1-\theta}{\theta} e^{\lambda \gamma_{3 t}+\gamma_{4 t}}+(1-\alpha)^{2} e^{\gamma_{2 t}}\left(1-e^{\gamma_{3 t}}\right)^{1-\alpha} \frac{e^{\gamma_{3 t}}}{1-e^{\gamma_{3 t}}} \\
& \frac{\partial \dot{\gamma_{2 t}}}{\partial \gamma_{4 t}}=\alpha \frac{1-\theta}{\theta} e^{\lambda \gamma_{3 t}+\gamma_{4 t}}
\end{aligned}
$$

$$
\begin{aligned}
\frac{\partial \dot{\gamma_{3 t}}}{\partial \gamma_{1 t}}= & \frac{1}{1-\lambda+\alpha \frac{e^{\gamma_{3} t}}{1-e^{\gamma_{3 t}}}} \alpha e^{\gamma_{1 t}} \\
\frac{\partial \dot{\gamma_{3 t}}}{\partial \gamma_{2 t}}= & \frac{1}{1-\lambda+\alpha \frac{e^{\gamma_{3 t}}}{1-e^{\gamma_{3 t}}}} \alpha e^{\gamma_{2 t}}\left(1-e^{\gamma_{3 t}}\right)^{1-\alpha}\left(\left(1-\tau_{v}\right) \theta-1\right) \\
\frac{\partial \dot{\gamma_{3 t}}}{\partial \gamma_{3 t}}= & \frac{1}{1-\lambda+\alpha \frac{e^{\gamma_{3 t}}}{1-e^{\gamma_{3 t}}}}\left(\alpha(1-\alpha) e^{\gamma_{2 t}}\left(1-e^{\gamma_{3 t}}\right)^{1-\alpha} \frac{e^{\gamma_{3 t}}}{1-e_{3 t}^{\gamma}}\left(1-\left(1-\tau_{v}\right) \theta\right)\right. \\
& \left.+e^{\lambda \gamma_{3 t}+\gamma_{4 t}} \lambda\left(\phi-\alpha \frac{1-\theta}{\theta}+(1-\theta) \frac{\alpha}{1-\alpha} \frac{1-e^{\gamma_{3 t}}}{e^{\gamma_{3 t}}}\right)-e^{\lambda \gamma_{3 t}+\gamma_{4 t}} \frac{\alpha}{1-\alpha} \frac{1-\theta}{e^{\gamma_{3 t}}}\right) \\
& \left.-\frac{\alpha}{1-e^{\gamma_{3 t}}} \frac{e^{\gamma_{3 t}}}{1-e^{\gamma_{3 t}}} \frac{1}{1-\lambda+\alpha \frac{e^{\gamma_{3 t}}}{1-e^{\gamma_{3 t}}}}\right) \\
\frac{\partial \dot{\gamma_{3 t}}}{\partial \gamma_{4 t}}= & \frac{1}{1-\lambda+\alpha \frac{e^{\gamma_{3 t}}}{1-e^{\gamma_{3 t}}}} e^{\lambda \gamma_{3 t}+\gamma_{4 t}}\left(\phi-\alpha \frac{1-\theta}{\theta}+(1-\theta) \frac{\alpha}{1-\alpha} \frac{1-e^{\gamma_{3 t}}}{e^{\gamma^{3 t}}}\right)
\end{aligned}
$$

$$
\begin{aligned}
& \frac{\partial \dot{\gamma_{4 t}}}{\partial \gamma_{1 t}}=0 \\
& \frac{\partial \dot{\gamma_{4 t}}}{\partial \gamma_{2 t}}=0 \\
& \frac{\partial \dot{\gamma_{4 t}}}{\partial \gamma_{3 t}}=-(1-\phi) \lambda e^{\lambda \gamma_{3 t}+\gamma_{4 t}} \\
& \frac{\partial \dot{\gamma_{4 t}}}{\partial \gamma_{4 t}}=-(1-\phi) e^{\lambda \gamma_{3 t}+\gamma_{4 t}}
\end{aligned}
$$

We can write the linearized system as

$$
\left(\gamma_{t}-\gamma^{*}\right) \approx \Gamma\left(\gamma_{t}-\gamma^{*}\right)
$$


$\Gamma=\left(\begin{array}{cccc}\frac{r^{*}+\delta}{\alpha \theta}-g-\delta & \frac{r^{*}+\delta}{\alpha \theta}\left(\alpha \theta \sigma\left(1-\tau_{v}\right)-1\right) & -\frac{r^{*}+\delta}{\theta}(1-\theta) \frac{\lambda n}{1-\phi} \frac{\alpha \theta \sigma\left(1-\tau_{v}\right)-1}{\rho+\frac{g-n}{\sigma}-\left(g-g_{A}\right)} & 0 \\ (1-\alpha)\left(\frac{r^{*}+\delta}{\alpha \theta}-g-\delta\right) & -(1-\alpha) \frac{r^{*}+\delta}{\alpha \theta} & \frac{\lambda n}{1-\phi} \frac{1-\theta}{\theta}\left(\alpha \lambda+(1-\alpha)\left(r^{*}+\delta\right)\right) & \alpha \frac{1-\theta}{\theta} \frac{\lambda n}{1-\phi} \\ x \alpha\left(\frac{r^{*}+\delta}{\alpha \theta}-g-\delta\right) & x \alpha \frac{r^{*}+\delta}{\alpha \theta}\left(\left(1-\tau_{v}\right) \theta-1\right) & \Gamma_{3,3} & \Gamma_{4,4} \\ 0 & 0 & -\lambda^{2} n & -\lambda n\end{array}\right)$

where $r^{*}$ is the steady-state interest rate from equation (12), and $g$ is the steady-state growth rate of output, capital and consumption; $x=\left(1-\lambda+\frac{\alpha^{2}}{1-\alpha}(1-\right.$ $\left.\theta) \frac{\lambda n}{1-\phi} \frac{1}{\left(1-\tau_{v}\right) r^{*}-\left(g-g_{A}\right)}\right)^{-1}$, and

$$
\begin{aligned}
\Gamma_{3,3}= & x\left(\alpha\left(r^{*}+\delta\right) \frac{1-\theta}{\theta} \frac{\lambda n}{1-\phi} \frac{1-\left(1-\tau_{v}\right) \theta}{\left(1-\tau_{v}\right) r^{*}-\left(g-g_{A}\right)}+\frac{\lambda^{2} \phi n}{1-\phi}-\right. \\
& \left.\frac{\alpha \lambda^{2} n}{1-\phi} \frac{1-\theta}{\theta}+\lambda\left(\left(1-\tau_{v}\right) r^{*}-\left(g-g_{A}\right)\right)\right)
\end{aligned}
$$

and

$$
\Gamma_{4,4}=x\left(\frac{\lambda^{2} \phi n}{1-\phi}-\frac{\alpha \lambda^{2} n}{1-\phi} \frac{1-\theta}{\theta}+\lambda\left(\left(1-\tau_{v}\right) r^{*}-\left(g-g_{A}\right)\right)\right)
$$

\section{A3. Solutions of the Linearized System}

The linearized system of equations is solved using the standard eigenvalue decomposition. Initial conditions for $K$ and $A$ generate the required boundary conditions to obtain the particular solution. 


\section{B Appendix: Longer Horizon Responses to a Tax Change}

This graph confirms that $s_{A}$ eventually converges to the new steady-state value. The share of labor working in the R\&D sector converges slowly and non-monotonically. When the tax rate falls, $s_{A}$ initially jumps up toward the new steady-state value. For several periods after than, as capital accumulates pushing up the marginal product of labor in final output, labor migrates back toward the final output sector. With the passage of time, the advance of the stock of designs increases (perceived) R\&D productivity so that workers are drawn back toward the R\&D sector. 
Figure 11: Labor Allocation Response to a Lower Tax Rate

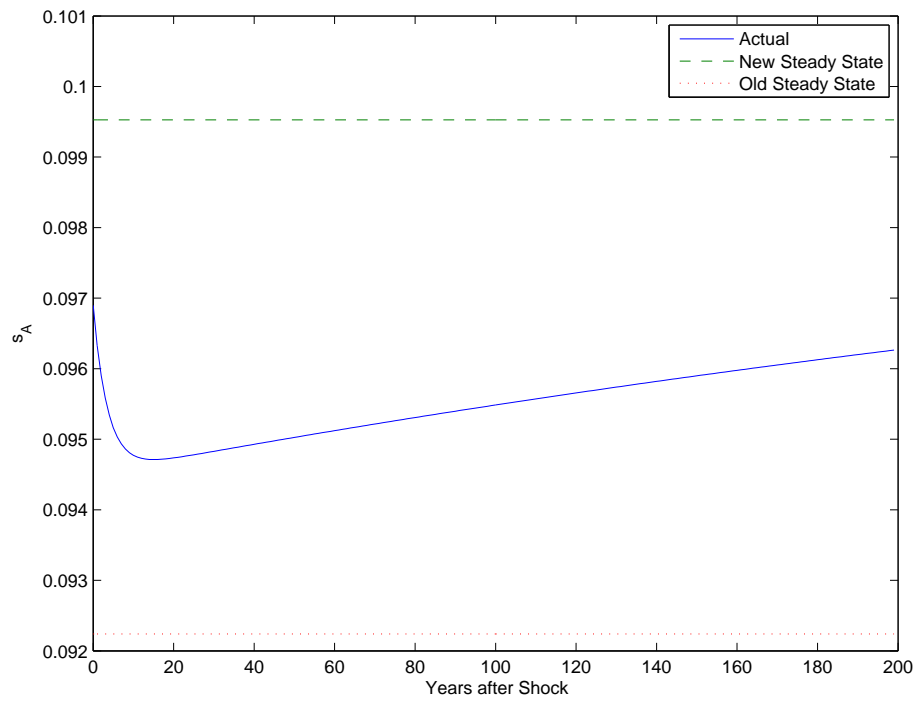




\section{References}

Agell, J. and M. Persson, "On the Analytics of the Dynamic Laffer Curve," Journal of Monetary Economics, 2001, 48 (2), 397-414.

Aghion, Philippe and Peter Howitt, "A Model of Growth through Creative Destruction," Econometrica, March 1992, 60 (2), 323-351.

Arnold, L. G., "The Dynamics of the Jones R \& D Growth Model," Review of Economic Dynamics, 2006, 9 (1), 143-152.

Auerbach, A. J., "Dynamic Revenue Estimation," Journal of Economic Perspectives, 1996, 10, 141-158.

_ and L. J. Kotlikoff, Dynamic Fiscal Policy, Cambridge University Press, 1987.

Barro, Robert J., "Government Spending in a Simple Model of Endogenous Growth," Journal of Political Economy, October 1990, 98, S103-S125.

Basu, Susanto and John G. Fernald, "Returns to Scale in U.S. Production: Estimates and Implications," Journal of Political Economy, April 1997, 105, 249-283.

Broda, C. and D. E. Weinstein, "Globalization and the Gains from Variety," Quarterly Journal of Economics, 2006, 121 (2), 541-585.

Bruce, N. and S. J. Turnovsky, "Budget Balance, Welfare, and the Growth Rate: "Dynamic Scoring" of the Long-Run Government Budget.," Journal of Money, Credit E Banking, 1999,31 (2), 162-163.

Chamley, C., "Optimal Taxation of Capital Income in General Equilibrium with Infinite Lives," Econometrica, 1986, pp. 607-622.

De Hek, P. A., “On Taxation in a Two-sector Endogenous Growth Model with Endogenous Labor Supply," Journal of Economic Dynamics and Control, 2006, 30 (4), 655-685.

Easterly, W. and S. Rebelo, "Fiscal Policy and Economic Growth," Journal of Monetary Economics, 1993, 32, 417-458.

Ferede, E., "Dynamic Scoring in the Ramsey Growth Model," The B. E. Journal of Economic Analysis \& Policy, 2008, 8 (1), 1948. 
Fullerton, D., "On the Possibility of an Inverse Relationship Between Tax Rates and Government Revenues," Journal of Public Economics, 1982, 19 (1), 3-22.

Goolsbee, A., "What Happens When you Tax the Rich? Evidence from Executive Compensation," Journal of Political Economy, 2000, 108 (2), 352-378.

Grossman, Gene M. and Elhanan Helpman, Innovation and Growth in the Global Economy, Cambridge, MA: MIT Press, 1991.

Hendricks, L., "Taxation and Long-run Growth," Journal of Monetary Economics, 1999, 43 (2), 411-434.

Ireland, P. N., "Supply-side Economics and Endogenous Growth," Journal of Monetary Economics, 1994, 33 (3), 559-571.

Jones, Charles I., "R\&D-Based Models of Economic Growth," Journal of Political Economy, August 1995, 103 (4), 759-784.

- , "Time Series Tests of Endogenous Growth Models," Quarterly Journal of Economics, May 1995, 110 (441), 495-525.

_ , "Growth: With or Without Scale Effects?," American Economic Association Papers and Proceedings, May 1999, 89, 139-144.

_ , "Growth and Ideas," in Philippe Aghion and Steven N. Durlauf, eds., Handbook of Economic Growth, Vol. 1B 2005, chapter 16, pp. 1063-1114.

- and John C. Williams, "Measuring the Social Return to R\&D," Quarterly Journal of Economics, November 1998, 113 (455), 1119-1135.

_ and _ , "Too Much of a Good Thing? The Economics of Investment in R\&D," Journal of Economic Growth, March 2000, 5 (1), 65-85.

Jones, L. E., R. E. Manuelli, and P. E. Rossi, "Optimal Taxation in Models of Endogenous Growth," Journal of Political economy, 1993, pp. 485-517.

_ , _ , and _ , "On the Optimal Taxation of Capital Income," Journal of Economic Theory, 1997, 73 (1), 93-117.

Judd, K., "Redistributive Taxation in a Simple Perfect Foresight Model," Journal of Public Economics, 1985, 28, 59-83. 
Lucas, Robert E., "On the Mechanics of Economic Development," Journal of Monetary Economics, 1988, 22 (1), 3-42.

Malcomson, James M., "Some Analytics of the Laffer Curve," Journal of Public Economics, April 1986, 29 (3), 263-279.

Mankiw, N.G. and M. Weinzierl, "Dynamic Scoring: A Back-of-the-Envelope Guide," Journal of Public Economics, 2006, 90 (8-9), 1415-1433.

Mendoza, E. G., G. M. Milesi-Ferretti, and P. Asea, “On the Ineffectiveness of Tax Policy in Altering Long-run Growth: Harberger's Superneutrality Conjecture," Journal of Public Economics, 1997, 66 (1), 99-126.

Milesi-Ferretti, G. M., "Growth Effects of Income and Consumption Taxes.," Journal of Money, Credit E Banking, 1998, pp. 721-722.

- and N. Roubini, "On the Taxation of Human and Physical Capital in Models of Endogenous Growth," Journal of Public Economics, 1998, 70 (2), 237-254.

Novales, A. and J. Ruiz, "Dynamic Laffer Curves," Journal of Economic Dynamics and Control, 2002, 27 (2), 181-206.

OECD, “OECD Tax Database,” www.oecd.org/ctp/taxdatabase 2011.

Pecorino, P., "Tax Rates and Tax Revenues in a Model of Growth Through Human Capital Accumulation," Journal of Monetary Economics, 1995, 36 (3), 527-539.

Romer, Paul M., "Endogenous Technological Change," Journal of Political Economy, October 1990, 98 (5), S71-S102.

Schmidt, G. W., Dynamics of Endogenous Economic Growth: A Case Study of the "Romer Model", North Holland, 2003.

Stokey, N. L. and S. Rebelo, "Growth Effects of Flat-tax Rates," Journal of Political Economy, 1995, 103 (3), 519-50. 